\title{
UNSERE ZEITSCHRIFT - EIN SCHAUFENSTER FÜR INNOVATIONEN
}

\section{Liebe Kolleginnen und Kollegen,}

Die Zeitschrift Akupunktur und Aurikulomedizin hat sich in den letzten Jahren zu einem echten „Marktplatz“ für Innovationen auch im Bereich der Traditionellen Chinesischen Medizin entwickelt. Nicht nur, dass tradiertes Wissen gut aufbereitet und anschaulich dargestellt wird, vielmehr werden auch moderne, zukunftsorientierte Lösungen beispielsweise für den Akupunkteur von morgen wissenschaftlich fundiert präsentiert. Ein Aufzählen von vorgestellten Neuentwicklungen allein im Bereich der Laserakupunktur würde den Rahmen dieses Vorworts sprengen.

Nur so viel zum Thema: Zielgenaue Forschungsförderung stärkt sowohl die Gesellschaften, die diese Forschungen finanzieren, als auch die Institutionen, die die Entwicklungsarbeiten durchfuihren. Als Paradebeispiel soll die Zusammenarbeit des TCM-Forschungszentrums an der Medizinischen Universität in Graz und der Deutschen Akademie für Akupunktur genannt werden, wenngleich der Blickwinkel natürlich voreingenommen ist (Abb. 1).

Firmen, seien diese beispielsweise im Bereich der Laserentwicklung oder auch einer anderen komplementärmedizinischenVerfahrensentwicklung angesiedelt, welche nicht in externe Forschung investieren, werden früher oder später mit ihrer Produktpalette wie eine unbewegte Masse stehen bleiben. Daher wieder einmal der Appell des Autors (G.L.) an alle, die zielgenaue Forschung ermögli-

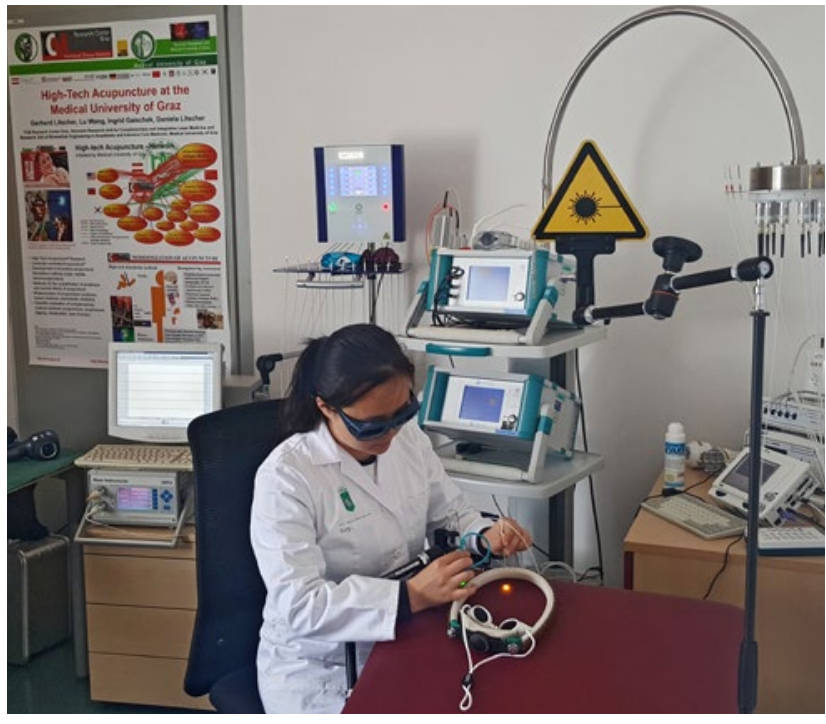

Abb. 1: Laserforschung auf dem Gebiet der Traditionellen Chinesischen Medizin an der Medizinischen Universität Graz

chen können und/oder wollen: Investieren Sie bitte auch in universitäre Forschung, denn Stillstand tut niemals gut, neue Ideen sind gefragt, Wissen schafft Wert.

In diesem Sinne: Freuen Sie sich auch in diesem Heft wieder auf spannende Berichte aus Forschung und Praxis

Mit herzlichen Grüßen

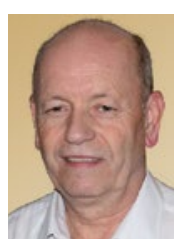

Dr. med. Dipl. Chem. Michael Weber

President for Medical and Clinical Applications der International Society for Medical Laser Applications (ISLAtranscontinental)

Klinik Neu-Mariahilf, Humboldtallee 10-12, D-37073 Göttingen, Tel. +49 5273/367 780

E-Mail: info@isla-laser.org, Internet:www.isla-laser.org

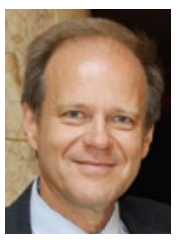

Univ.-Prof. Prof. h.c. DI Dr. techn.

Dr. scient. med.Gerhard Litscher

President for Science and Research der International Society

for Medical Laser Applications (ISLAtranscontinental)

Medizinische Universität Graz, Auenbruggerplatz 29,

A-8036 Graz, Tel: +43 316/385-13907, -83907

E-Mail:gerhard.litscher@medunigraz.at, Internet:http://litscher.info 